\title{
Extracorporeal shockwave therapy in a dog with chronic bicipital tenosynovitis
}

\author{
Venzin, Claudio ; Ohlerth, Stefanie ; Koch, D ; Spreng, D
}

\begin{abstract}
A 15-month-old, spayed female, Bernese mountain dog was presented to the Institute of Small Animal Surgery at the University of Zurich because of chronic left forelimb lameness. The referring veterinarian diagnosed pain in the left shoulder region and had treated the dog with systemic non-steroidal anti-inflammatory drugs and restricted exercise for a two-week period. The follow-up examination revealed only minimal improvement and therefore, the dog was referred for further diagnostic evaluation. Chronic bicipital tenosynovitis and tendinitis of the infraspinatus muscle was diagnosed based on survey radiographs, arthrography, ultrasound, computed tomography (CT), and synovial fluid cytology. The dog underwent three sessions of extracorporeal shockwave therapy and substantial clinical improvement was observed. On follow-up examinations, only mild left forelimb lameness was evident following exercise, and changes in the intertubercular groove and at the supraglenoid tuberosity appeared less active on radiographs and CT. However, six months following treatment, mild degenerative joint disease was apparent.
\end{abstract}

DOI: https://doi.org/10.1024/0036-7281.146.3.136

Posted at the Zurich Open Repository and Archive, University of Zurich

ZORA URL: https://doi.org/10.5167/uzh-63117

Journal Article

Published Version

Originally published at:

Venzin, Claudio; Ohlerth, Stefanie; Koch, D; Spreng, D (2004). Extracorporeal shockwave therapy in a dog with chronic bicipital tenosynovitis. Schweizer Archiv für Tierheilkunde, 146(3):136-141.

DOI: https://doi.org/10.1024/0036-7281.146.3.136 


\title{
Extracorporeal shockwave therapy in a dog with chronic bicipital teno- synovitis
}

\author{
C.Venzin'1, S. Ohlerth², D. Koch'3 ${ }^{3}$ D. Spreng ${ }^{1}$ \\ 1Division of Small Animal Surgery and 'Division of Diagnostic Imaging and Radio-Oncology, University of Berne, \\ 3Division of Small Animal Surgery, University of Zurich
}

\section{Summary}

A 15-month-old, spayed female, Bernese mountain dog was presented to the Institute of Small Animal Surgery at the University of Zurich because of chronic left forelimb lameness. The referring veterinarian diagnosed pain in the left shoulder region and had treated the dog with systemic nonsteroidal anti-inflammatory drugs and restricted exercise for a two-week period. The follow-up examination revealed only minimal improvement and therefore, the dog was referred for further diagnostic evaluation. Chronic bicipital tenosynovitis and tendinitis of the infraspinatus muscle was diagnosed based on survey radiographs, arthrography, ultrasound, computed tomography (CT), and synovial fluid cytology. The dog underwent three sessions of extracorporeal shockwave therapy and substantial clinical improvement was observed. On follow-up examinations, only mild left forelimb lameness was evident following exercise, and changes in the intertubercular groove and at the supraglenoid tuberosity appeared less active on radiographs and CT. However, six months following treatment, mild degenerative joint disease was apparent.

Key words: Bernese mountain dog, bicipital tenosynovitis and tendonitis of the infraspinatus muscle, shockwaves, CT

\section{Extrakorporale Stosswellentherapie bei einem Hund mit chronischer Sehnenscheiden- entzündung}

Eine 15 Monate alte weiblich-kastrierte Bernersennenhündin wurde wegen chronisch progressiver Lahmheit im Tierspital Zürich vorgestellt. Der Privattierarzt diagnostizierte Schmerz in der linken Schulterregion und hatte den Hund mit nicht steroidalen Entzündungshemmern und Bewegungseinschränkung während 2 Wochen vorbehandelt. Diese Behandlung zeigte nur minimale Besserung, darum wurde der Hund für weitere Abklärungen überwiesen. Eine chronische Sehnenscheidenentzündung des M. biceps brachii und des M. infraspinatus wurde mittels Röntgennativaufnahme, Arthrographie, Ultraschall, Computertomographie (CT) und Zytologie der Synovialflüssigkeit diagnostiziert. Der Hund wurde mit drei extrakorporalen Stosswellensessionen behandelt und zeigte daraufhin klinisch eine deutliche Besserung. Bei der Nachuntersuchung zeigte der Hund nur noch eine geringe Lahmheit in der vorderen linken Gliedmasse und die Veränderungen im Schultergelenk waren auf dem Kontrollröntgen und dem Kontroll-CT weniger aktiv. Sechs Monate nach Behandlung waren trotzdem geringe degenerative Gelenksveränderungen sichtbar.

Schlüsselwörter: Bernersennenhund, Sehnenscheidenentzündung, $M$. biceps brachii und $M$. infraspinatus, Stosswellen, Computertomographie

\section{Case presentation}

A 15-month-old, spayed female Bernese mountain dog was presented to the Clinic of Small Animal Surgery at the University of Zurich with a history of progressive lameness over several weeks. The referring veterinarian noted severe, grade 3 out of 4, lameness in the left forelimb, localized to the region of the shoulder joint. Radiographs of the shoulder joints taken by the referring veterinarian demonstrated bilateral mineralised periarticular structures, which were more pro-

nounced on the left side. The dog was treated with carprofen (Rimadyl ${ }^{\mathbb{R}}$, Pfizer) $4 \mathrm{mg} / \mathrm{kg} / \mathrm{d}$ for two weeks and the owner was advised to restrict the dog to leash walks. No substantial improvement in the degree of lameness was observed in this short time of treatment for a chronic lameness and the client was then referred.

At presentation, the general physical examination was unremarkable. The orthopaedic examination revealed 

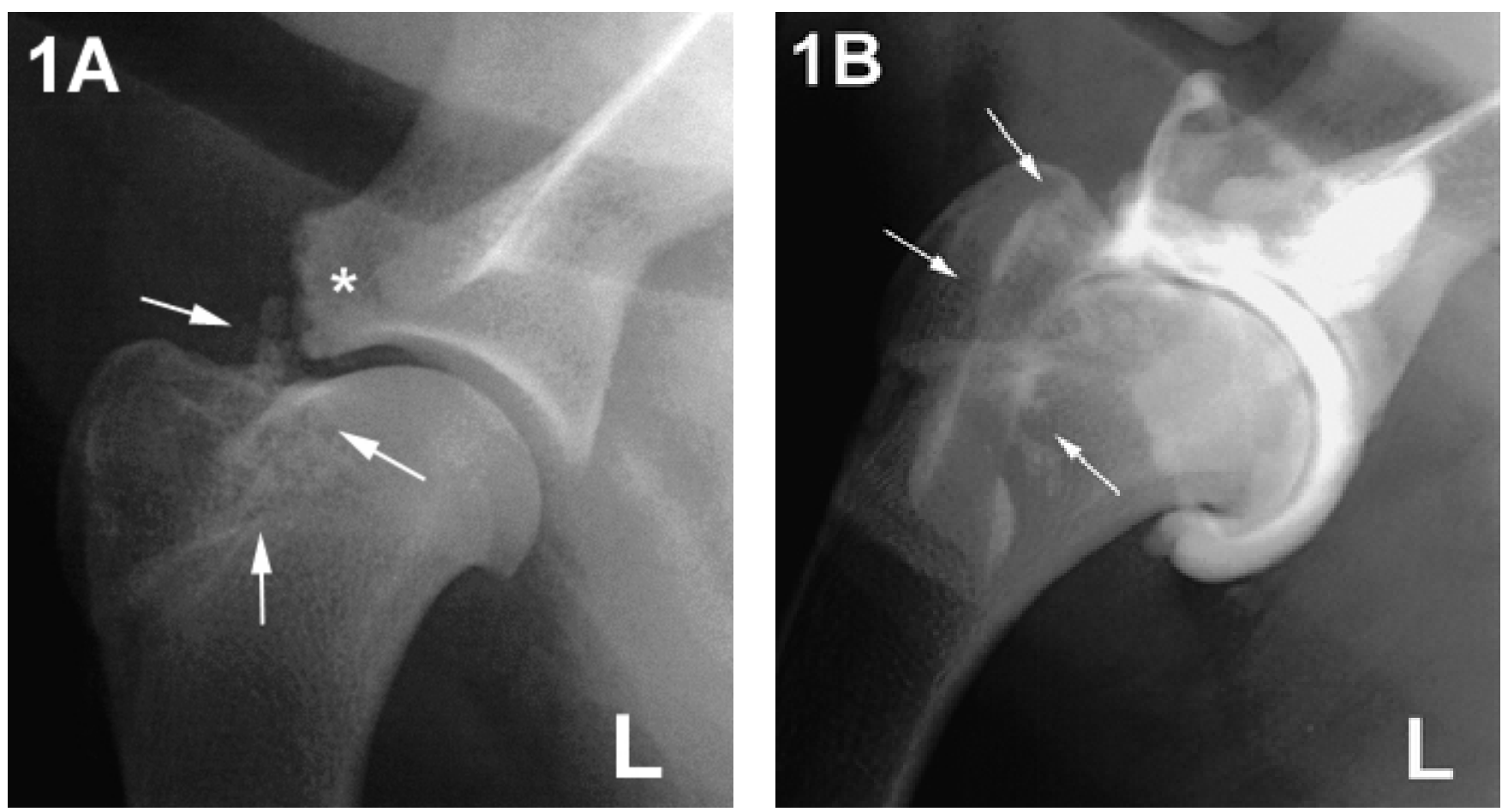

Figure 1: Mediolateral radiographs of the left shoulder joint prior to ESWT: the survey radiograph (Figure 1A) shows severe irregularity of the supraglenoid tuberosity (asterix) and the intertubercular groove as well as enthesophyte formation along the bicipital groove (arrows). The arthrogram (Figure 1B) demonstrates a very irregular tendon sheath with poor filling (arrows).

a left forelimb lameness in the region of the left shoulder joint that was considered grade 3 of 4 in severity. Gait analysis revealed a decreased forward stride. Flexion of the shoulder joint with concurrent extension of the elbow elicited signs of severe pain on the left side and minimal pain on the right side. Pressure applied on the biceps tendon in the region of the intertubercular groove also elicited severe pain. The left supraspinatus and infraspinatus muscles appeared mildly atrophied. Based on these findings, left bicipital tenosynovitis was suspected. The dog was sedated with acepromazine (Prequillan, Fatro) $0.02 \mathrm{mg} / \mathrm{kg}$ and butorphanol (Morphasol, Gräub) $0.2 \mathrm{mg} / \mathrm{kg}$ intramuscular injection and survey radiographs including mediolateral, caudocranial and craniodistal-cranioproximal flexed views of both shoulder joints were taken. Radiographs of the left shoulder (Fig. 1A) revealed severe irregularity of the supraglenoid tuberosity and the intertubercular groove, and enthesophyte formation along the bicipital groove and at the insertion site of the infraspinatus muscle. Signs of degenerative joint disease were not detected. Radiographs of the right shoulder showed similar but less severe changes. The radiographic findings were indicative of severe chronic left bicipital tenosynovitis, insertion tendinitis of the left infraspinatus muscle and mild right bicipital tenosynovitis. A chronic partial tear of the bicipital tendons close to their origin or avulsion could not be excluded.

Subsequently, ultrasonographic evaluation of the left biceps muscle was performed, confirming the radio- graphic diagnosis. Findings included multiple hyperechogenic irregular structures with acoustic shadowing in the bicipital groove and mild filling of the tendon sheath. The bicipital tendon appeared mildly inhomogeneous at its origin and the supraglenoid tubercle appeared irregular.

Finally, positive-contrast arthrography of both shoulder joints was performed as previously described (Suter and Carb, 1969) to exclude the presence of corpora libera.The contrast medium used was Iotrolan (Isovist ${ }^{\circledR}$ 240, Schering AG) at a concentration of $100 \mathrm{mg} / \mathrm{ml}$ and an injected volume of $4 \mathrm{ml}$. Arthrograms included mediolateral views of the shoulder joints in neutral, flexed and extended positions and a caudocranial view. The left bicipital tendon sheath appeared very irregular and good filling was not obtained (Fig. 1B). The arthrogram of the right shoulder appeared normal. Synovial fluid was aspirated from both shoulders for cytological examination, which revealed changes consistent with degenerative joint disease with a mild inflammatory component in the left shoulder (nucleated cell count 1200/ $\mu$; specific gravity 1.022; total protein $26 \mathrm{~g} / \mathrm{L}$; differential cell count: $84 \%$ monocytes, $10 \%$ lymphocytes, $4 \%$ nondegenerate neutrophils and $2 \%$ eosinophils). For the right shoulder joint cytological examination the results were within the normal limits. Brinker et al. described that one third of cases treated medically had to be treated a second time with medications or required a surgical treatment. 


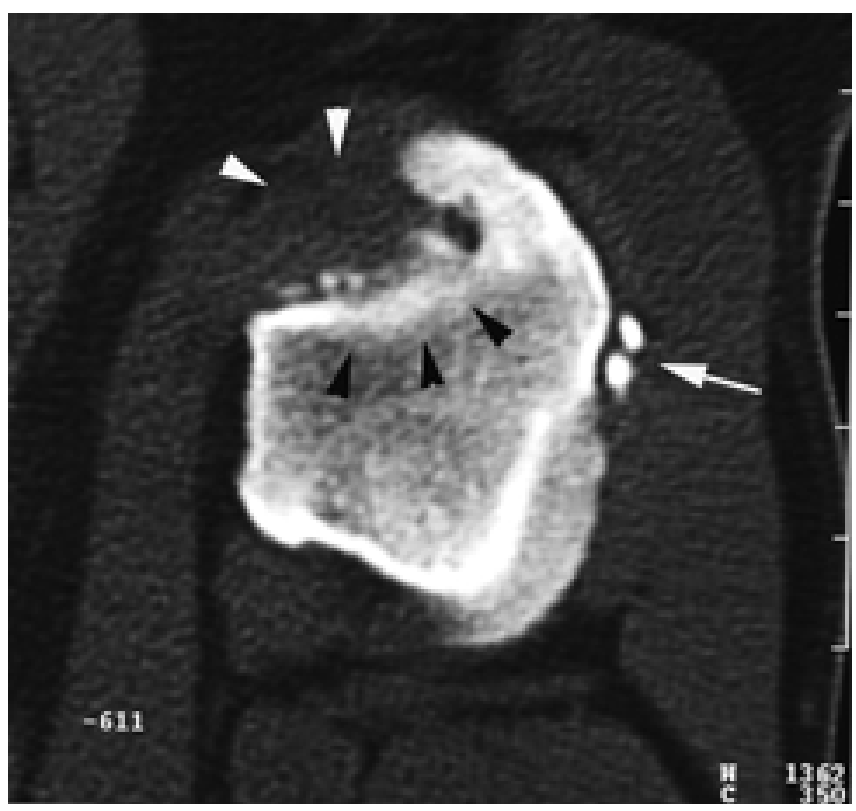

Figure 2: Transverse CT scan of the left bicipital groove prior to ESWT: enthesophyte formation along the bicipital groove (black arrowheads) and within the infraspinatus muscle (white arrow) is seen. The bicipital tendon and tendon sheath are not well delineated (white arrowheads).

The client declined surgical intervention but was willing to undertake a trial with extracorporeal shockwave therapy (ESWT).

The dog was sedated with acepromazine (Prequillan, Fatro) $0.02 \mathrm{mg} / \mathrm{kg}$ and butorphanol (Morphasol, Gräub) $0.2 \mathrm{mg} / \mathrm{kg}$ intramuscular, and anaesthesia was induced with intravenous propofol (Disoprivan ${ }^{\circledR}$, Fresenius). Following endotracheal intubation, inhalation anaesthesia was maintained with isoflurane (Forene ${ }^{\circledR}$, Abbott) delivered in $100 \%$ oxygen. Prior to therapy, computed tomography (CT) of both shoulder joints was performed, demonstrating multiple round structures of mineral density distal to both supraglenoid tubercles, in both bicipital grooves and laterally to the greater tubercle at the insertion site of the left infraspinatus muscle. Findings were more prominent in the left shoulder joint (Fig. 2). The left tendon was mildly displaced in a craniolateral direction due to the space-occupying mineral dense structures. The structure and the origin of the bicipital tendon were difficult to assess. However, gross abnormalities were not noted. The dog was then positioned in lateral recumbency for ESWT. One thousand shockwaves with an energy density of $0.2 \mathrm{~mJ} / \mathrm{mm}^{2}$ (Equitron ${ }^{\circledR}$, High Medical Technologies) were applied to the regions in which mineralization was detected. The dog had an uneventful anaesthetic recovery and was discharged from hospital the next day. Follow-up inquiries were conducted with the client by telephone who reported a marked improvement in the dog's general attitude and reduction of lameness beginning four weeks after therapy.
ESWT was repeated eight weeks after the first session. At this time, the dog had mild left forelimb lameness, localized to the shoulder joint that was considered grade 1 out of 4 in severity. Follow-up radiographs of both shoulder joints were obtained prior to treatment. The supraglenoid tuberosity was regular and smooth and the mineralised structures at the supraglenoid tuberosity and in the intertubercular groove appeared more rounded, smooth, and less active. However, the mineralization structures were unchanged in size and number (Fig. 3).A third ESWT session was performed after a subsequent eight weeks. Survey radiographs of both shoulder joints taken at this time revealed no further changes in the structure or density of the mineralised structures compared to the previous radiographs. An orthopaedic examination performed six months after the last ESWT revealed minimal lameness in the left forelimb that was only detectable following exercise. Minimal signs of pain were elicited on flexion of the shoulder joint and concurrent extension of the elbow, what pointed to a bicipital tendonitis. The dog was again anaesthetised and radiographs and CT of both shoulder joints were performed, demonstrating mild progression of entheseophyte formation and mild osteophyte formation on the caudal articular margins of the left joint. Findings in the right joint were unchanged.

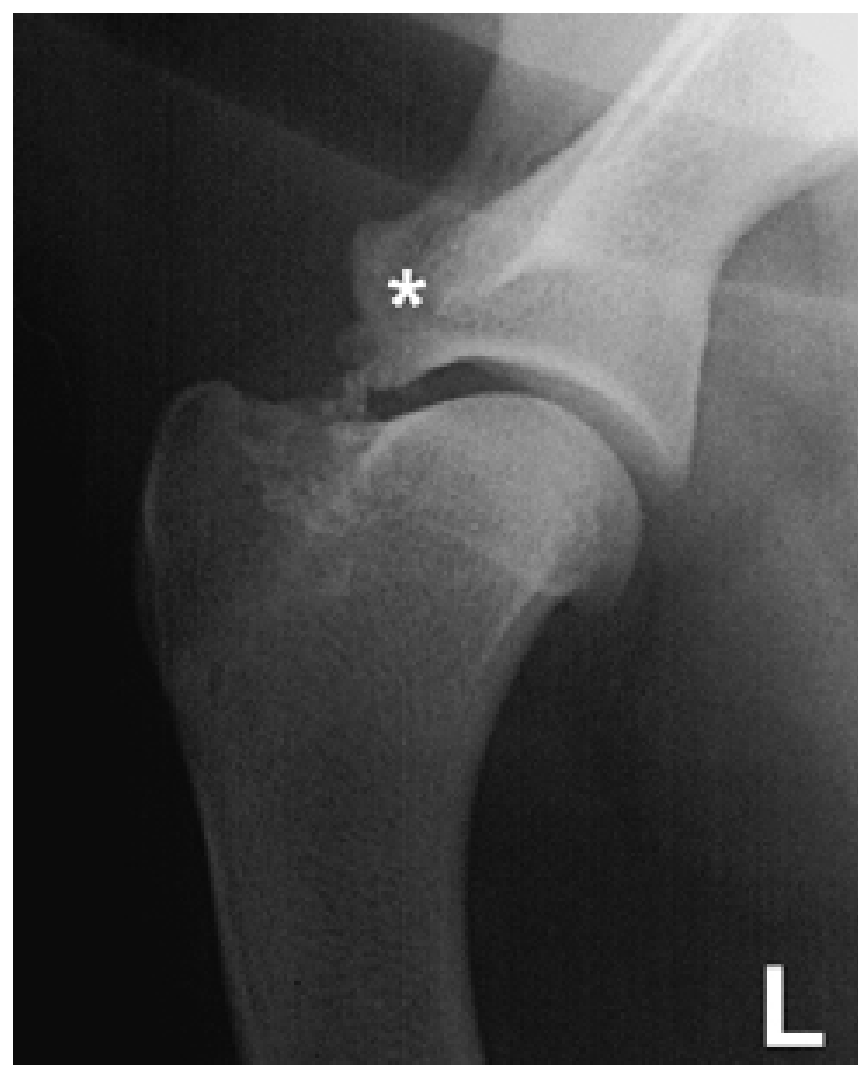

Figure 3: Mediolateral radiograph of the left shoulder joint 8 weeks after the first ESWT session, prior to the second session: the supraglenoid tuberosity (asterix) is smooth and regular, the mineralised structures along the intertubercular groove are unchanged in number and size, but appear more rounded and less active. 


\section{Discussion}

The causes of primary bicipital tenosynovitis and of calcifying tendinopathies have not been fully elucidated. Various authors have suggested a relationship between these disorders and overuse, chronic repetitive trauma or high biomechanical stress followed by an inflammatory response (Neviaser, 1980; Post and Benca, 1989; Flo and Middleton, 1990; Brinker et. al., 1997).

It has been theorized that tendon trauma, such as chronic partial rupture, may initiate alterations in local blood supply leading to focal hypoxia. Hypoxia may then trigger remodelling of tendon collagen into fibrocartilage with subsequent chondrocyte-mediated osteogenesis (Muir et al.,1992). Stress and overuse of the tendon may cause degenerative changes that undergo dystrophic mineralization, causing inflammation in peritendinous tissues (Cofield, 1985 ).

Diagnostic evaluations of tendinopathies include survey radiography, contrast arthrography, ultrasonography, CT, magnetic resonance imaging (MRI) and diagnostic arthroscopy. Survey radiographs are only useful to demonstrate the extent of bony changes. Contrast arthrography, however, is useful in identifying selected abnormalities associated with bicipital tenosynovitis in the dog (Rivers et al., 1992; Barthez and Morgan, 1993). Filling defects along the tendon correspond to proliferative synovium, adhesions between the tendon and the tendon sheath or the formation of joint mice (LaHue et al., 1988; Brinker et. al., 1992; Rivers et al., 1992). Ultrasonographic examinations have proven very useful in the evaluation of tendon disorders and surrounding soft tissues (Kramer et. al., 2001). In the present report, ultrasonography provided the most information regarding the bicipital tendon and tendon sheath. Computed tomography has also been shown to be a valuable diagnostic tool in equine musculoskeletal diseases, including tendinopathies (Whitton et. al., 1998; Tucker and Sande, 2001). In general, CT is thought to be more sensitive in evaluating soft tissue mineralization or bony lysis because of its high contrast resolution, and osteolysis and osteogenesis can be detected before changes are perceived on conventional radiographs (Tucker and Sande, 2001). In the present case, however, the authors' impression was that CT was most helpful in determining the localization of the mineralized structures and survey radiographs proved the most sensitive method to monitor changes in the size, shape and density of mineralized structures. This was thought to be due to the small size of the structures of interest causing volume averaging artifacts in the CT studies. Further, the structure and the origin of the bicipital tendons was difficult to assess with $\mathrm{CT}$ in the present case, most likely due to volume averaging artifacts and limited spatial resolution. In human medicine, MRI has become the method of choice to evaluate soft tissue structures of the shoulder joint.

The primary objective of the treatment in the patient in this report was to reduce the degree of inflammation of the biceps tendon and its synovial sheath. The most effective treatment for tenosynovitis is not yet clear (Vasseur et. al.,1983; Resnick, 1988; Post and Benca, 1989;). Nonsurgical management includes exercise restriction, physiotherapy, systemic nonsteroidal anti-inflammatory drugs and the intrasynovial administration of corticosteroids (Farrow, 1978; Piermattei, 1980; Davis and Jones, 1982; Lincoln and Potter, 1984). Although local steroid treatment in humans can provide dramatic clinical relief (Cox and Paterson, 1991), its use in small animals is controversial (Uthhoff et. al., 1976; Murphy et. al., 2000). It may predispose to tendon weakening and hence tendon rupture (Balasubramaniam and Prathap, 1972). Injections of steroids into the tendon itself are contraindicated as it has been shown that this can cause further necrosis and degeneration of the tendon (Balasubramaniam and Prathap, 1972; Nizdeck and White, 1981; Chunekamrai et. al., 1989; Clark, 1991; Kriegleder, 1995; Stobie et. al., 1995).

Extracorporeal shock wave therapy has been extensively used in human medicine for lithotripsy and more recently for the treatment of degenerative arthropathies (Haupt, 1997). In addition, ESWT has been used in horses affected with osteoarthritis of the tarsometatarsal joint (McCarroll and McClure, 2002) and dogs with tendinopathy (Danova and Muir, 2003). To date, three different hypotheses have been proposed to explain the mechanism of action of ESWT. The gate control theory (Fields and Basbaum, 1999) proposes that ESWT causes hyperstimulation of nerve axons, which leads to an increased pain threshold and subsequent analgesic effect. It is presumed that if this is the case, pain is not transmitted because local cellular destruction impedes the production of generation potentials. A massive stimulation of nociceptors leads to a massive increase in nerve impulses causing an overflow and blockage of nerve conduction in the central nervous system. The second theory suggests that ESWT leads to a stimulation of vascularization with changes in membrane permeability leading to increased metabolic processes. In this instance, the generation of free radicals leads to changes in the chemical environment, inducing the production of pain inhibitors. The third theory proposes that ESWT can destroy mineralized particles, such as calcifications in tendons, by changes in pressure that are produced by the energy of the shock wave within microseconds. Shock waves cause microscopic lesions, 
known as cavitation bubbles, within the targeted tissues. These bubbles then collapse causing a fluid jet that leads to additional damage to the surface of the target. Local metabolic rate and circulation are thought to be enhanced by this mechanism (Hepp et al., 1991).

The patient described in this case report was treated with ESWT following unsuccessful medical therapy. Diagnostic imaging revealed that the mineralized structures in the region of the intertubercular groove and the supraglenoid tuberosity itself appeared less active after the first session of ESWT. However, the two additional treatment sessions did not demonstrate any improvement in the radiographic appearance of the joint. This finding is consistent with previous reports, which suggest that only one session of ESWT can be beneficial (Rope, 1997). Rompe and co-workers (1997) demonstrated that only $50 \%$ of the patients with tendinosis calcarea of the shoulder joint enjoyed a disintegration of the calcifications 12 weeks after ESWT (Rope, 1997).

The dog in the present report was observed to have a substantial clinical improvement, having only minimal lameness during heavy exercise 8 weeks after the first treatment. During normal activity, the dog remained free of lameness. Minimal pain could be elicited with maximum flexion of the shoulder joint and concurrent extension of the elbow. Pain could no longer be produced by palpation of the biceps tendon. The considerable improvement in the degree of lameness observed in the dog in this report may have been, in part, due to long-term exercise restriction. The authors therefore assume that ESWT was largely responsible for the clinical outcome in this case.

Disadvantages to this treatment modality include the necessity for general anaesthesia, dictated by the painful nature of the treatment and the need for absence of movement during ESWT applications. The authors assume that ESWT could prove to be a valid and useful alternative for the treatment of chronic arthropathies. Controlled experimental and clinical studies in dogs are necessary to establish the extent to which ESWT can be recommended in a clinical setting.

\section{References}

Balasubramaniam P., Prathap K.: The effect of injection of hydrocortisone into rabbit calcaneal tendons. J. Bone Joint Surg. Am., 1972, 54B: 729-734.

Barthez P.Y., Morgan J.P.: Bicipital tenosynovitis in the $\operatorname{dog}-$ evaluation with positive contrast arthrography. Vet. Radiol. Ultrasound, 1993, 34:325-330.

BrinkerW. O., Piermattei D. L., Flo G. L.: Handbook of small animal orthopedics and fracture treatment.3nd ed. Sauders W. B., Co, Philadelphia. 1997: 249-260.

Chunekamrai S., Krook L.P., Lust G., et. al.: Changes in articular cartilage after intra-articular injections of methylprednisolone acetate in horses. Am. J. Vet. Res., 1989, 50: 1733-1741.

Clark D. M.: Current concepts in the treatment of degenerative joint disease. Comp. Cont. Educ. Pract. Vet., 1991, 13: 1439-1446.

Cofield R. H.: Rotator cuff disease of the shoulder. J. Bone Joint Surg. Am., 1985, 67: 974-979.

Cox D., Paterson F.W.N.: Acute calcific tendonitis of peroneus longus. J. Bone Joint Surg. Am., 1991, 73B: 342.

Danova N. A., Muir P.: Extracorporal shock wave therapy for supraspinatus calcifying tendinopathy in two dogs.Vet.Rec., 2003,152: 208-209.
Davies J. V., Jones D. G. C.: Triceps tendon rupture in the dog following corticosteroid injection. J. Small Anim. Pract., 1982, 23: 779-787.

Farrow C. S.: Sprain, strain, and contusion.Vet. Clin. North Am., 1978, 8: 169-182.

Flo G. L., Middleton D.: Mineralisation of the supraspinatus tendon in dogs. J. Am.Vet. Med. Assoc., 1997,197: 95-97.

Fields H. L., Basbaum A. I.: Central nervous system mechanisms of pain modulation. In: Textbook of Pain. Melzack, R., Wall, P.D. (eds). Churchill Livingstone. 1999, pp: 309-329.

Haupt G.: Use of extracorporeal shock waves in the treatment of pseudoarthrosis, tendinopathy and other orthopedic diseases. J. Urol., 1997, 158: 4-11.

Hepp W., Grünewald M., Brendel W.: Die extrakorporale Stosswellenlithotripsie. Spektrum der Wissenschaft 1991 , 44-53.

Kramer M., Gerwig M., Sheppard C. :Ultrasonography for the diagnosis of diseases of the tendon and tendon sheath of the biceps brachii muscle.Vet. Surg., 2001, 30: 64-71.

Kriegleder H.: Mineralisation of the supraspinatus tendon: Clinical observations in seven dogs. Vet. Comp. Orthop. Traumatol., 1995: 8, 91-97. 
LaHue T.R., Roush J. C., Ticer J.W. Entrapment of joint mice in the bicipital tendon sheath as a sequela to osteochondritis dissecans of the proximal humerus in a dog: a report of six cases. J.Am.Vet. Med.Assoc., 1988, 24:99-105.

Lincoln J. D., Potter K.: Tendosynovitis of the biceps brachii tendon in dogs. J.Am.Vet. Med. Assoc., 1984: 20, 385-392.

McCarroll G. D., McClure S. R.: Initial experiences with extracorporeal shock wave therapy for treatment of bone spavin in horses part II. Vet. Comp. Orthop. Traumatol., 2002,15: 184-186.

Muir P., Goldsmid S.E., Rothwell T.L.W., et. al.: Calcifying tendinopathy of the biceps brachii in a dog. J.Am.Vet. Med. Assoc., 1992, 201: 1747-1749.

Murphy D. J., Todhunter R. J., Fubini S. L., et. al.: The effects of methylprednisolone on normal and monocyte-conditioned medium-treated articular cartilage from dogs and horses.Vet. Surg., 2000, 29: 546-557.

Neviaser R. J.: Lesions of the biceps and tendonitis of the shoulder. Orthop. Clin. North Am., 1980, 11:343--348.

Neviaser T.J.: The role of the biceps tendon in the impingement syndrom. Orthop. Clin. North Am., 1987,18: 383 386.

Nizdeck D. J.H., White K. K.: Corticosteroids and hyaluronic acid treatments in equine degenerative joint disease.A review. The CornellVeterinarian, 1981,71:355-375.

Piermattei D. L.: Orthopedic Conditions of the Shoulder Region, in: Proceedings of the American Animal Hospital Association Annual Meeting, 1980, 47:371.

Post M., Benca P.: Primary tendonitis of the long head of the biceps. Clin. Orthop., 1989, 246:117-125.
Resnick D.: Calcium hydroxyapatie crystal deposition disease. In: Diagnosis of bone joint disorders. $2^{\text {nd }}$ ed.WB Sauders Co, Philadelphia 1988, pp.1733-1764.

Rivers B., Wallace L., Johnston G. R.: Biceps tenosynovitis in the dog: adiographic and sonographic findings. Vet. Comp. Orthop. Traumatol., 1992, 5: 51-57.

Rompe J. D. : Tendinosis calcarea der Schulter. In: Extrakorporale Stosswellentherapie .J.D. Rompe. Chapman und Hall GmbH Weinheim. 1997 pp127-149.

Stobie D., Wallace L.J., Lipowitz A.J.: Chronic bicipital tenosynovitis in dogs: 29 cases (1985-1992).J.Am.Vet. Med. Assoc., 1995, 207: 201-207.

Suter P.F, Carb A.V.: Shoulder arthrography in dogs: radiographic anatomy and clinical application. J. Small Anim. Pract., 1969,10: 407-413.

Tucker R.L., Sande R.D.: Computed tomography and magnetic resonance imagine of the equine musculoskeletal conditions. Vet. Clin. North Am. Equine Pract., 2001, 17 145-157.

Uhthoff H. K., Sarkar K., Maynard J. A.: Calcifying tendinitis: a new concept of its pathogenesis. Clin. Orthop., 1976, 118: 164-168.

Vasseur P. B., Pool R. R., Klein K.: Effects of tendon transfer on the canine scapulohumeral joint. Am. J.Vet. Res., 1983, 44: 811-815.

Whitton R. C., Buckley C., Donovan T.: The diagnosis of lameness associated with distal limb pathology in a horse: a comparison of radiography, computed tomography and magnetic resonance imaging.Vet. J., 1998, 155: 223-229.

\section{Corresponding author}

Claudio Venzin, Abteilung für Chirurgie, Departement für klinische Veterinärmedizin, Universität Bern Länggassstr. 128, CH-3012 Bern,Telefon 00413163123 15, Fax 0041316312375

E-Mail: claudio.venzin@kkh.unibe.ch

Received for publication: 25 June 2003

Accepted in final form: 2 September 2003 